\title{
The impact of optical radiation of femtosecond duration on human glial cells
}

Diana B. Ilatovskaia, Yuri B. Porozov, Petr S. Demchenko, Igor V. Meglinski, Mikhail K. Khodzitsky

Diana B. llatovskaia, Yuri B. Porozov, Petr S. Demchenko, Igor V. Meglinski, Mikhail K. Khodzitsky, "The impact of optical radiation of femtosecond duration on human glial cells," Proc. SPIE 10820, Optics in Health Care and Biomedical Optics VIII, 108203G (23 October 2018); doi: 10.1117/12.2502601

SPIE. Event: SPIE/COS Photonics Asia, 2018, Beijing, China 


\title{
The impact of optical radiation of femtosecond duration on human glial cells
}

\author{
Diana B. Ilatovskaia*a, Yuri B. Porozov ${ }^{\text {b,c }}$, Petr S. Demchenko ${ }^{\text {a }}$, Igor V. Meglinsky ${ }^{\text {a,d }}$, Mikhail K. \\ Khodzitsky ${ }^{\mathrm{a}}$ \\ ${ }^{a}$ Terahertz Biomedicine Laboratory, Photonics and Optical Information Department, ITMO \\ University, 3B Kadetskaia line, St. Petersburg, 199034, Russia \\ ${ }^{\mathrm{b}}$ The Laboratory of Bioinformatics, ITMO University, 49 Kronversky ave., St. Petersburg, 197101, \\ Russia \\ ${ }^{c}$ I. M. Sechenov First Moscow State Medical University, The Laboratory of Bioinformatics, 8-2 \\ Trubetskaya str., Moscow 119991, Russia \\ ${ }^{d}$ Optoelectronics and Measurement Techniques Unit, Faculty of Information Technology and \\ Electrical Engineering, University of Oulu, P.O. Box 4500, FI-90015, Oulu, Finland
}

\begin{abstract}
The paper presents the results of the studies of influence of optical radiation with wavelengths of 520 and $780 \mathrm{~nm}$ on human glial cells (U251) at the range of exposure times $\sim 1-15 \mathrm{~min}$. It was found that after the first minute of irradiation at the wavelength of $780 \mathrm{~nm}$, the relative number of apoptotic cells significantly increased. The result corroborates the concept of biological hazard of optical radiation for tumor cells, and suggests that the approach has a great potential in clinical application for the treatment of human glioma.
\end{abstract}

Keywords: Irradiation, glioma, cell line U251, cytochrome C oxidase, apoptosis, pulse IR radiation, resonance effect

\section{INTRODUCTION}

Glioma is the most aggressive and difficult for treatment type of cancer. Malignant glioma cells of the U251 line were originally detected in a 75-year-old patient with multiple glioblastomas in the 70s of the last century [1]. These cells evolved into glioblastomas, histochemically and genetically repeating human disease, when introduced to animals [2]. Malignant gliomas represent one of the most aggressive forms of brain cancer [3]. They are difficult to treat and often resistant to conventional radio- and chemotherapy [4]. Despite application of common treatment procedures, surgery is included [5], the survivability of patients with tumors of the type remains low [6].

High-grade glioma features are rapid proliferation, angiogenesis, and invasive growth. Eradication or inhibition of infiltrating glioma cells poses a significant clinical challenge, unlikely to be solved using conventional treatment regimens consisting of ionizing radiation and chemotherapeutic agents [7]. The most promising treatment technique is the photodynamic therapy (PDT). Though its use in treating brain tumors dates back to 1980 [8-11], the results of clinical trials are ambiguous, partly because of their limited scope. Almost universally, the PDT is administered as a single treatment immediately after the surgery. In most cases, the treatment failure ensues due to local recurrence. This indicates that a more aggressive local treatment may prove more efficient as about $80 \%$ tumors recur within $2 \mathrm{~cm}$ of the resection cavity [12].

The radiation therapy is believed to be the most advanced, though having specific limitations, since both soft brain and cranial osseous tissues absorb the radiation. In the paper [13] it was shown that the radiation at wavelengths of 670 and $830 \mathrm{~nm}$ stimulated proliferation of Schwann cells (the glial cells of peripheral nervous system) [14], but the radiation at wavelength of $780 \mathrm{~nm}$ inhibited these.

Optics in Health Care and Biomedical Optics VIII, edited by Qingming Luo, Xingde Li, Ying Gu, Yuguo Tang, Dan Zhu, Proc. of SPIE Vol. 10820, 108203G · (C) 2018 SPIE · CCC code: 0277-786X/18/\$18 · doi: 10.1117/12.2502601 
The effect of continuous wave radiation with wavelength of $635 \mathrm{~nm}$ was studied earlier [7]. In this study, the effects of 5-aminolevulinic acid (ALA)-mediated photodynamic therapy (PDT) on the invasiveness of human glioma cells migrating from implanted multicell human tumor spheroids were evaluated. Measurement of cell survival, and results from cultures with blocked cell proliferation, indicated a direct migratory inhibition effect on the invading cells.

The article [15] reports the phototoxicity effects of a novel photosensitizer ZnPcS4-BSA on human U251 glioma cells in vitro at wavelength of $670 \mathrm{~nm}$ with energy density of $25,50,100,150$ and $200 \mathrm{~J} / \mathrm{cm}^{2}$.

Also, the influence of THz and IR radiation on human brain tumor was studied in [16, 17]. Since liquids absorb THz and IR radiation easily, the method cannot be used in non-invasive manner.

Recently, the increasing interest in studying cells, tissues, and embryos using femtosecond laser pulses took place. This is related to the fact that for multiphoton absorption, femtosecond pulses in the visible and near-infrared region can be used, where transparency window for biological objects is situated [18]. In addition, dissection, ablation, and microsurgery on various biological objects can be conducted with minimal heating and sometimes even without it. This circumstance is of fundamental character, since heat leads to uncontrollable destructive processes. Moreover, the optimal mode for femtosecond pulses in microsurgery consists of pulses with a small peak power and high repetition rate.

In this paper we have used optical radiation of femtosecond duration at wavelengths of $520 \mathrm{~nm}$ and $780 \mathrm{~nm}$ with exposure time of 1-15 min to control the number of glial cells effectively.

\section{SAMPLE PREPARATION AND ANALYSIS}

The study of U251 human glioma cell line included the cultivation of cells and used DMEM medium supplemented with $10 \%$ fetal calf serum (FCS), $40 \mu \mathrm{g} / \mathrm{ml}$ of gentamicin, and $2 \mathrm{mM}$ of L-glutamine.

During experiments, the cells were seeded into wells of a 24-well flat-bottomed plate (Sarstedt AG \& Co. KG, Germany). 20 wells of the plate were exposed, whereas samples in 4 wells were used as control ones. The irradiation was performed at a cell monolayer density of $50 \%$. After irradiation, the cells were incubated at $37{ }^{\circ} \mathrm{C}$ in atmosphere of $5 \%$ $\mathrm{CO} 2$ for 24 hours.

The assessment of changes in mitochondrial membrane potential was performed after the stage of samples preparation. The technique bases on the use of two fluorescent dyes, methyl tetramethyl-rhodamine (TMRM) and DNA-binding dye DRAQ7 [19]. The effect causes a change in the cell fluorescence intensity in the red-orange portion of the spectrum with maximum emission wavelength of $573 \mathrm{~nm}$, which is recorded with a cytofluorometer. For detect different stages of apoptosis (in addition to TMRM), cells are additionally stained with DRAQ7, a dye being capable of interacting with cell nucleic acids. DRAQ7 cannot diffuse through the bilipid membranes and, hence, contact with DNA of the cells. A consequence of the interaction is the dye accumulation in the cytoplasm and nucleus, whereby the cell takes on fluorescence in the red part of spectrum. It should be noted that a diode laser with an emission wavelength of $638 \mathrm{~nm}$ was used to efficiently excite the dye, whereas the detection of the signal from DRAQ7 after its binding to the ligands was recorded at a wavelength of $725 \pm 20 \mathrm{~nm}$.

Thus, live cells have bright fluorescence through a channel designed to detect TMRM, but do not accumulate DRAQ7 (the phenotype TMRMhigh/DRAQ7-). Cells at the early stages of apoptosis when the mitochondrial potential decreases, but the plasma membrane still retains its integrity and impermeability for DRAQ7, have the TMRMlow/DRAQ7phenotype. However, the late apoptotic and necrotic cells do not efficiently accumulate TMRM, but are stained DRAQ7 (the phenotype TMRMlow/DRAQ7+).

To evaluate the mitochondrial membrane potential the cell labeling procedures were performed. It was taken $20 \times$ solution of TMRM with added to $100 \mu \mathrm{l}$ cell suspension $(2-3 \times 106 \mathrm{cells} / \mathrm{ml})$ at the final concentration of $150 \mathrm{nM}$. The working solution prepared ex tempore, adding $9990 \mu \mathrm{l}$ of PBS and $10 \mu \mathrm{l}$ of the stock solution. The incubation completed, $200 \mu \mathrm{l}$ of PBS were added to the samples, and cytometric analysis was performed. It was classical method of cell labeling presented in work [20]. 
The next stage of experiment was to perform cytofluorometry analysis. The Navios Flow Cytofluorometer was employed for sample analysis. For each sample, at least 10000 single cells were analyzed. The results were analyzed with Navios software. The result was expressed as a percentage of the total number of cells analyzed and was presented as an average with an error in the form of mean error (Mean \pm SEM). The samples were compared using the Student $t$-test. Differences were considered significant at $\mathrm{p}<0.05$.

\section{EXPERIMENTAL SETUP AND PROCESS}

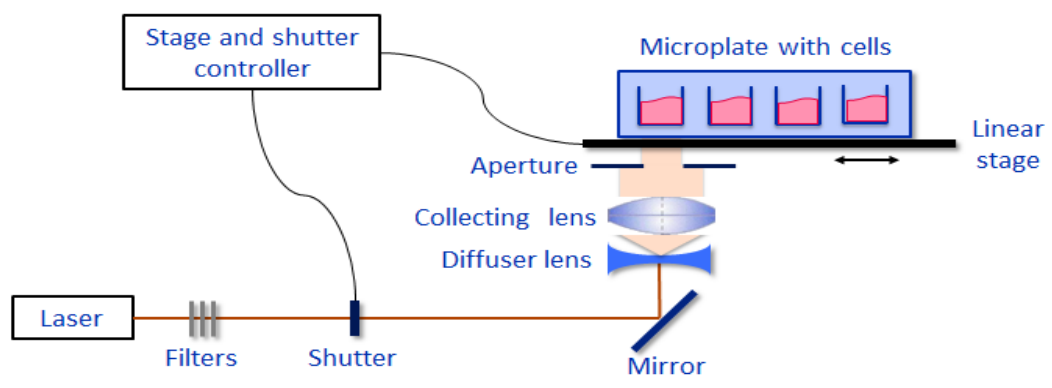

Fig.1. Experimental scheme of setting.

The scheme for setting of irradiation has shown in Fig. 1. The beam of IR laser radiation passes through the filters and comes to the shutter, which is controlled by the stage and shutter controller via PC. To control the power and duration of irradiation, a special software was written in LabView. When the shutter is opened, the IR beam passes through it to the system of mirrors and enters the diffuser and collecting lenses. Afterwards, the light beam propagates through the aperture of the same diameter as wells, $1.7 \mathrm{~cm}$. This helps to avoid irradiation of other wells. Every line includes one control well, not subjected to the irradiation.

Two IR femtosecond lasers were used in the experiment. The first one is Fiber-based "Avesta project EFOA-SH" with wavelength of $1560 \mathrm{~nm} / 780 \mathrm{~nm}(2 \mathrm{H})$, average power up to $130 \mathrm{~mW}$, pulse duration of $120 \mathrm{fs}$. The second one is "SolarLS FL-1" with wavelength of $1040 \mathrm{~nm} / 520 \mathrm{~nm}(2 \mathrm{H})$, average power up to $1000 \mathrm{~mW}$, pulse duration of $200 \mathrm{fs}$. Repetition rates are the same, $70 \mathrm{MHz}$. The exposition of the cell line U251 was performed in both cases at the average power of $45 \mathrm{~mW}$.

\section{EXPERIMENTAL SETUP AND PROCESS}

To analyze the results, two-dimensional histograms of TMRM fluorescence intensity were plotted. According to the data shown in Table 1, Table 2 and Fig.2, the number of cells with actively functioning mitochondria (phenotype TMRM high/DRAQ7-) in samples exposed to radiation remains practically unchanged. An increase in the irradiation time leads to a significant decrease in the number of such cells in the sample in one of the three experiments performed with the maximum irradiation time (15 minutes). The number of cells with a reduced ability to accumulate the mitochondrial dye (the "TMRM low" phenotype) significantly decreased in the corresponding experiment at the same point of time. It should be noted that the population of cells with the phenotype "TMRM low/DRAQ7 +" exhibited no significant changes in the test samples against the control ones. 

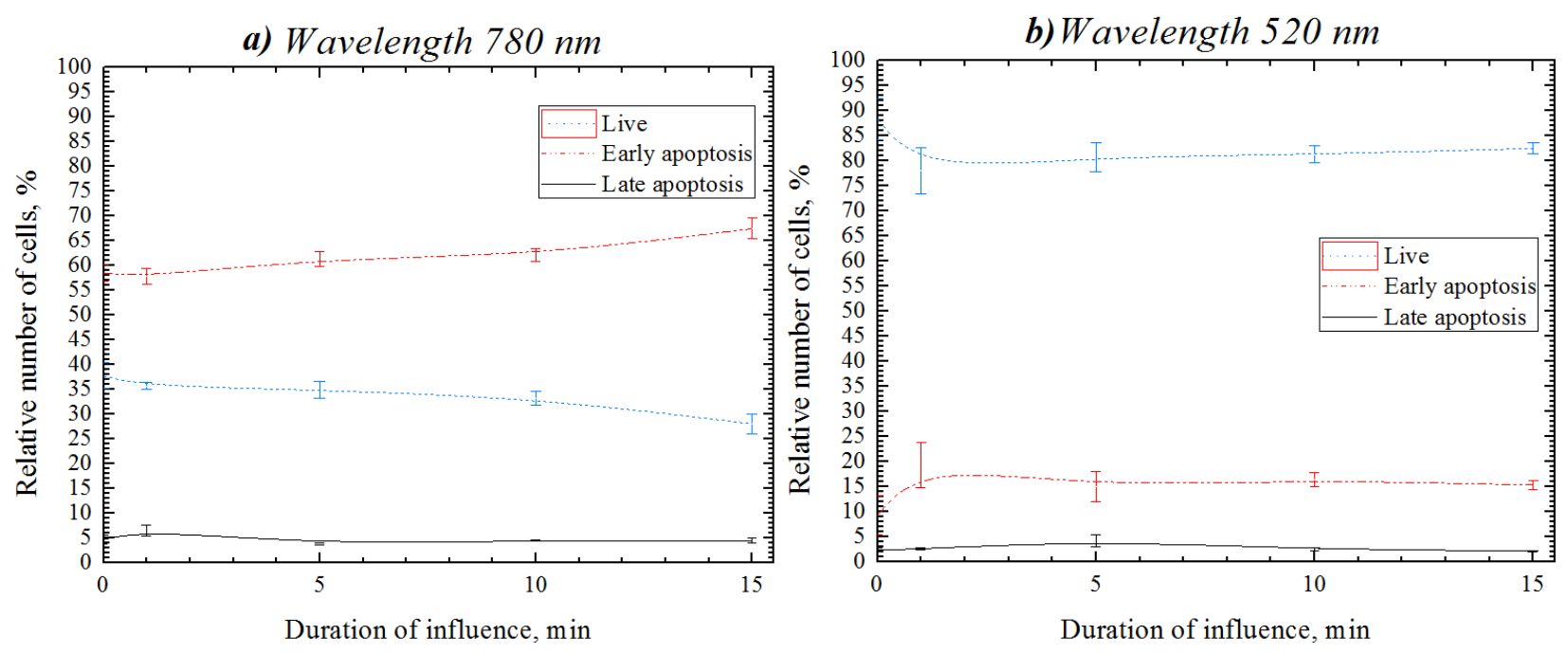

Fig.2. The percentage of cells in solution (live, early apoptosis and late apoptosis / necrosis) vs. the exposure time at wavelengths of $780 \mathrm{~nm}$ (a) and $520 \mathrm{~nm}(\mathrm{~b})$

The quantities in both figures (Fig. 2) tend to stabilize after 1 minute. The number of early apoptosis cells starts to increase in the experiment with the wavelength of $780 \mathrm{~nm}$.

Table 1. Percentage of live cells and cells at different stages of apoptosis in samples. The irradiation was performed at wavelength of $520 \mathrm{~nm}$ for different durations (Mean \pm SEM, $\mathrm{n} \geq 4$ )

\begin{tabular}{|l|l|l|l|}
\hline \multirow{2}{*}{$\begin{array}{l}\text { Exposure, } \\
\text { min. }\end{array}$} & Live cells & Early apoptotic cells & Late apoptotic/necrotic cells \\
\cline { 2 - 4 } & (TMRM high/DRAQ7-) & (TMRM low/DRAQ7-) & (TMRM low/DRAQ7+) \\
\hline 0 & $88,27 \pm 4,02$ & $9,30 \pm 3,90$ & $2,37 \pm 0,41$ \\
\cline { 1 - 1 } & $77,96 \pm 4,55$ & $19,38 \pm 4,56$ & $2,62 \pm 0,17$ \\
\cline { 1 - 1 } & $80,72 \pm 2,96$ & $15,08 \pm 2,99$ & $4,20 \pm 1,22$ \\
\hline 10 & $81,26 \pm 1,63$ & $16,40 \pm 1,43$ & $2,56 \pm 0,21$ \\
\hline 15 & $82,46 \pm 1,04$ & $15,36 \pm 0,95$ & $2,18 \pm 0,14$ \\
\hline
\end{tabular}

Table 2. Percentage of live cells and cells at different stages of apoptosis in samples. The irradiation was performed at wavelength of $780 \mathrm{~nm}$ for different durations (Mean \pm SEM, $\mathrm{n} \geq 4$ )

\begin{tabular}{|l|l|l|l|}
\hline \multirow{2}{*}{$\begin{array}{l}\text { Exposure, } \\
\text { min. }\end{array}$} & Live cells & Early apoptotic cells & Late apoptotic/necrotic cells \\
\cline { 2 - 4 } & (TMRM high/DRAQ7-) & (TMRM low/DRAQ7-) & (TMRM low/DRAQ7+) \\
\cline { 1 - 1 } & $37,75 \pm 2,61$ & $58,48 \pm 1,68$ & $4,73 \pm 0,86$ \\
\cline { 1 - 1 } 5 & $35,66 \pm 0,70$ & $57,74 \pm 1,61$ & $6,58 \pm 1,11$ \\
\cline { 1 - 1 } 10 & $34,88 \pm 1,68$ & $61,28 \pm 1,54$ & $3,84 \pm 0,26$ \\
\cline { 1 - 1 } & $33,30 \pm 1,38$ & $62,08 \pm 1,31$ & $4,56 \pm 0,11$ \\
\hline
\end{tabular}


The present study has convincingly demonstrated the increase of apoptotic cell number along with the reduction of the number of living cells in the sample under the application of radiation at a wavelength of $\lambda=780 \mathrm{~nm}$. We attribute this selective effect of optical radiation to the influence on molecules of cytochrome $\mathrm{C}$ at the absorption frequency [21] (Fig. 3). Cytochrome $\mathrm{C}$ in complex with the cardiolipin is known to be located on the inner surface of the mitochondrial membrane. As Tiina Karu notes [22], there are enough chromatophores in the cytochrome $\mathrm{C}$ oxidase molecule (Cu and $\mathrm{Mg}$ atoms, heme groups). We suggest that the influence by radiation with $\lambda=780 \mathrm{~nm}$ can launch a cascade of intramitochondrial reactions. This is triggered by a change in the conformational-physical state of cytochrome $\mathrm{C}$ oxidase and lor its electron transportation function due to the absorption and, possibly, the resonance effect (temporal changes in hydrogen bond structure, change in charge and possibly secondary structure). This leads to a drastic change in peroxidase activity of Cytochrome $\mathrm{C}$, an increase of hydroperoxides on cardiolipin and subsequent dissociation of the cytochrome C-cardiolipin complex. Further reactions in the mitochondria and cytoplasm of the cell can follow several metabolic pathways. Somehow, each of them is connected with the development of early apoptosis: formation of NO and active forms of oxygen (mitochondrial ROS), increase of mitochondrial membrane permeability, release of cytochrome $\mathrm{C}$ into the cytoplasm and its binding with the protein Apaf-1 and ATP, as well as with pro-caspase 9 (apoptosome formation) followed by its activation (pro-caspase 9 transition into the active form of caspase 9) and activation of effector caspase 3.

Thus, we suggest that a resonance effect on the U251 cell culture triggers the metabolic cascade of spontaneous apoptosis. The trigger is a change in the physical properties of the cytochrome $\mathrm{C}$ oxidase and, possibly, a local change in its secondary structure.
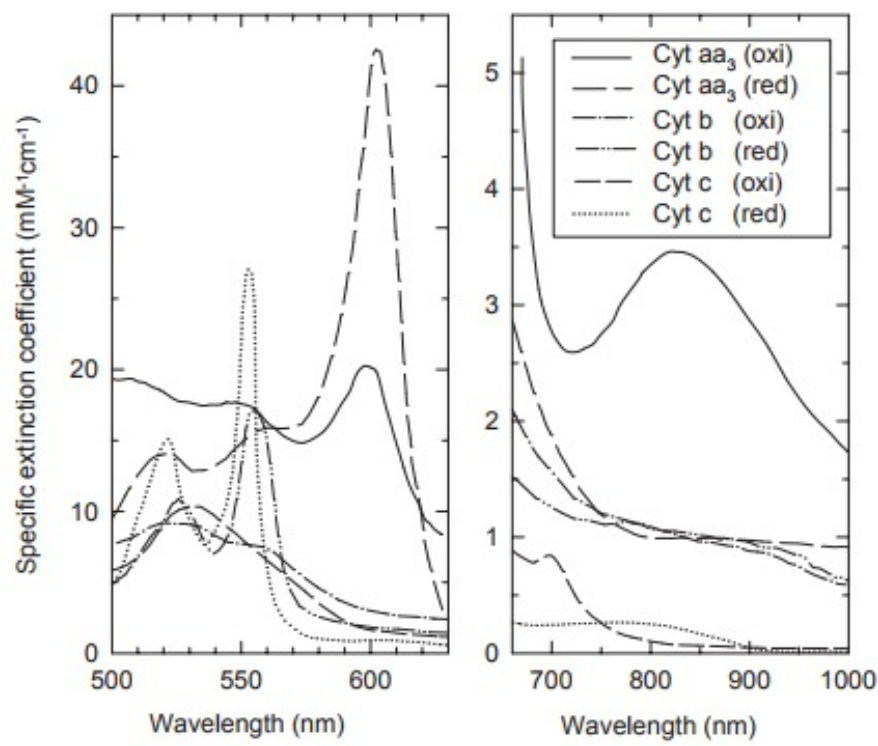

Fig.3. Specific extinction coefficient spectra of cytochrome $\mathrm{C}$ oxidase, cytochrome $\mathrm{b}_{5}$ and the $\mathrm{C}$ (per function unit) [25].

\section{CONCLUSION}

The influence of optical radiation (the wavelengths of 520 and $780 \mathrm{~nm}$ and exposure times 1-15 min.) on human glial cells (U251) was studied in the research. As a result of the study it was found that number of apoptotic cells increases by approximately $10 \%$ upon irradiation at the wavelength of $780 \mathrm{~nm}$ after 1 minute of influence.

The hypotheses are assumed, why the observed effect takes place. Thus, we suggest that a resonance effect on the U251 cell culture triggers the metabolic cascade of spontaneous apoptosis. The trigger is a change in the physical properties of the cytochrome $\mathrm{C}$ oxidase and, possibly, a local change in its secondary structure.

The result corroborates the concept of biological hazard of optical radiation on oncology cells. 


\section{REFERENCES}

[1] J. Pontén, "Neoplastic human glia cells in culture. In Human tumor cells in vitro," Springer, Boston, MA, 175-206 (1975).

[2] V.L. Jacobs, P.A. Valdes, W.F. Hickey, and J.A. De Leo, "Current review of in vivo GBM rodent models: emphasis on the CNS-1 tumour model," ASN Neuro 3(3), (2011).

[3] S. Dai, S. Hu, and C. Wu, "Apoptotic effect of sonodynamic therapy mediated by hematoporphyrin monomethyl ether on C6 glioma cells in vitro," Acta Neurochirurgica 151(12), 1655-1661 (2009).

[4] D. Koul, R. Shen, S. Bergh, X. Sheng, S. Shishodia, T. A. Lafortune, Y. Lu, J. F. de Groot, G. B. Mills and W.K. A. Yung, "Inhibition of Akt survival pathway by a small-molecule inhibitor in human glioblastoma," Mol. Cancer Ther. 5, 637-644 (2006).

[5] A. Boiardi, A. Silvani, I. Milanesi, M. Botturi, G. Broggi, "Primary glial tumor patients treated by combining cisplatin and etoposide", Journal of neuro-oncology. 11(2), 165-170 (1991).

[6] Y. Kondo, E.F. Hollingsworth, and S. Kondo, "Molecular targeting for malignant gliomas (Review)," Int. J. Oncol. 24, 1101-1109 (2004)

[7] H. Hirschberg, C.H. Sun, T. Krasieva, and S.J. Madsen, "Effects of ALA-mediated photodynamic therapy on the invasiveness of human glioma cells," Lasers Surg. Med. 38(10), 939-945 (2006).

[8] A. Albini, Y. Iwamoto, H.K. Kleinman, G.R. Martin, S.A. Aaronson, J.M. Kozlowski, et al. "A rapid in vitro assay for quantitating the invasive potential of tumor cells", Cancer Res. 47, 3239-3245 (1987)

[9] A.P. Amar, S.J. DeArmond, D.R. Spencer, P.F. Coopersmith, D.M. Ramos, and M.L. Rosenblum, "Development of an in vitro extracellular matrix assay for studies of brain tumor cell invasion," J. Neurooncol. 20, 1-15 (1994).

[10] F. Jiang, M. Chopp, M. Katakowski, K.-K. Cho, X. Yang, N. Hochbaum, L. Tong, and T. Mikkelsen, "Photodynamic therapy with Photofrin reduces invasiveness of malignant human glioma cells," Lasers Med. Sci. 17, 280-288 (2002).

[11] C. Schichorl, S. Kerkau, T. Visted, R. Martini, R. Bjerkvig, C. Tonn, and R. Goldbrunner, "The brain slice chamber, a novel variation of the Boyden Chamber Assay, allows time-dependent quantification of glioma invasion into mammalian brain in vitro," J. Neurooncol. 73, 9-18 (2005).

[12] C. Nieder, A.L. Grosu, and M. Molls, "A comparison of treatment results for recurrent malignant gliomas," Cancer Treatment Reviews 26, 397-409 (2000)

[13] Karu, T. (1999). Primary and secondary mechanisms of action of visible to near-IR radiation on cells. Journal of Photochemistry and photobiology B: Biology, 49(1), 1-17

[14] Dai, Y., \& Hill, C. E. (2018). Transplantation of Adult Rat Schwann Cells into the Injured Spinal Cord. In Schwann Cells (pp. 409-438). Humana Press, New York, NY.

[15] Xu, D., Ke, Y., Jiang, X., Cai, Y., Peng, Y., \& Li, Y. (2010). In vitro photodynamic therapy on human U251 glioma cells with a novel photosensitiser ZnPcS4-BSA. British journal of neurosurgery, 24(6), 660-665.

[16] M. Borovkova, M. Serebriakova, V. Fedorov, E. Sedykh, V. Vaks, A. Lichutin, A. Salnikova, and M. Khodzitsky, "Investigation of terahertz radiation influence on rat glial cells," Biomed. Opt. Exp. 1, 273-280 (2017).

[17] S. Her, D.A. Jaffray, and C. Allen, "Gold nanoparticles for applications in cancer radiotherapy: Mechanisms and recent advancements," Advanced Drug Delivery Reviews 109, 84-101 (2017).

[18] Hamblin, M. R., \& Demidova, T. N. (2006, February). Mechanisms of low level light therapy. In Mechanisms for low-light therapy (Vol. 6140, p. 614001). International Society for Optics and Photonics

[19] J. Akagi, M. Kordon, H. Zhao, A.Matuszek, Dobrucki, R. Errington, P.J. Smith, K. Takeda, Z. Darzynkiewicz, and D. Wlodkowic, "Real-time cell viability assays using a new anthracycline derivative DRAQ7®," Cytometry Part A 83(02), 227-234 (2013).

[20] Horan, Paul Karl, Meryle J. Melnicoff, Bruce D. Jensen, and Sue E. Slezak. "Fluorescent cell labeling for in vivo and in vitro cell tracking." In Methods in cell biology, vol. 33, pp. 469-490. Academic Press, 1990.

[21] M.G. Mason, P. Nicholls, C.E. Cooper, "Re-evaluation of the near infrared spectra of mitochondrial cytochrome c oxidase: implications for non invasive in vivo monitoring of tissues," Biochimica et Biophysica Acta Bioenergetics 1837(11), 1882-1891 (2014).

[22] T.I. Karu, "Multiple roles of cytochrome c oxidase in mammalian cells under action of red and IR-A radiation," IUBMB Life 62(8), 607-610 (2010). 


\section{FUNDING}

The work was financially supported by the Government of Russian Federation, Grant 08-08.

\section{ACKNOWLEDGMENTS}

The authors are grateful to staff of Academic writing Laboratory of ITMO University for polishing of English language, to Mr. Alexey Trofimov for his help with experiments and to Ms. Maria Serebriakova and Irina Asadullina for medical consultations.

Proc. of SPIE Vol. 10820 108203G-7

Downloaded From: https://www.spiedigitallibrary.org/conference-proceedings-of-spie on 16 Jul 2019 Terms of Use: https://www.spiedigitallibrary.org/terms-of-use 